\title{
Long-term effects of radioiodine on thyroid function, size and patient satisfaction in non-toxic diffuse goitre
}

\author{
Steen J Bonnema, Viveque E Nielsen and Laszlo Hegedüs \\ Department of Endocrinology and Metabolism, Odense University Hospital, DK-500O Odense C, Denmark \\ (Correspondence should be addressed to S Bonnema; Email: steen.bonnema@dadlnet.dk)
}

\begin{abstract}
Objective: The long-term effects of ${ }^{131}$ I-therapy in patients with symptomatic non-toxic diffuse goitre were evaluated.

Design and methods: In a prospective open study, 34 patients (median age: $40 \mathrm{yrs}$, range: $27-68 \mathrm{yrs)}$ were enrolled who suffered from a non-toxic goitre absent of nodules on clinical examination and on ultrasonography. Treatment indication was the presence of goitre giving rise to cervical compression and/or cosmetic discomfort. The median ${ }^{131}$ I activity was $600 \mathrm{MBq}(200-600 \mathrm{MBq})$ administered orally on an outpatient basis. The patients were investigated by clinical examination, thyroid ultrasonography and thyroid function tests at regular intervals and for at least 12 months after the ${ }^{131} \mathrm{I}$ therapy. Yearly follow-up continued until the end of the study period or if permanent hypothyroidism ensued. The severity of symptoms was evaluated by a Visual Analogue Scale (VAS) (range: 0-10). Results: The median follow-up time was 36 months (12-84). Goitre volume was reduced from $67.9 \pm 28.5 \mathrm{ml}$ to $43.4 \pm 18.7 \mathrm{ml}($ mean \pm S.D. $)(P<0.001) 3$ months after the ${ }^{131}$ I-therapy. After 3 years of follow-up, only $28.1 \pm 2.0 \%$ (mean \pm S.E.) remained of the initial goitre mass $(P<0.001)$. Goitre was no longer present in $76 \%$ of the patients at the end of follow-up. An inverse correlation was found 1 year after therapy, but not after 3 years, between the initial goitre size and the percent reduction $(r=-0.44, P=0.01)$. Thirty-six percent had become hypothyroid after three years. Median VAS scores were reduced from an initial 7.0 (cervical compression) and 5.5 (cosmetic discomfort) to 0.0 at the end of follow-up $(P<0.001)$.

Conclusion: Our data justify treatment of non-toxic diffuse goitre with ${ }^{131} \mathrm{I}$ because goitre reduction is pronounced, along with a very high degree of patient satisfaction and few side effects. We suggest that ${ }^{131}$ I-therapy can be used as an alternative to $\mathrm{L}-\mathrm{T}_{4}$ suppressive therapy and thyroidectomy in this group of patients.
\end{abstract}

European Journal of Endocrinology 150 439-445

\section{Introduction}

Non-toxic goitre is common and appears endemically in areas with a low iodine intake. There are scarce epidemiological data concerning non-toxic diffuse goitre and furthermore we know little of the quality of life in those who have undergone the standard treatment modalities. Indications for treatment in this disorder comprise pressure symptoms and/or cosmetic complaints, as a result of continuous goitre growth. When treatment is indicated, for whatever reason, the traditional recommendations are long-term levothyroxine (L- $\left.\mathrm{T}_{4}\right)$ suppression therapy or thyroidectomy. $\mathrm{L}_{-} \mathrm{T}_{4}$ suppressive therapy is extensively used as a treatment of choice in patients with non-toxic diffuse goitre. The effect of this treatment, with or without the addition of triiodothyronine, is not impressive with a 20-30\% reduction of the thyroid size within 3-9 months (1-3). Serum thyroid-stimulating hormone (s-TSH) must be reduced to below the reference range in order to obtain the maximum effect (4). This again leads to tissue thyrotoxicosis, which is associated with serious adverse health problems $(5,6)$. Furthermore, the treatment needs to be life-long if regrowth is to be hindered $(1,4)$. Thyroid surgery efficiently reduces goitre size but carries a risk of both surgical and anaesthetic complications. Damage to the recurrent laryngeal nerves and hypoparathyroidism occurs in $1-2 \%$, a risk that increases with large goitres or in case of reoperation (7).

${ }^{131}$ I-therapy, used mainly for the treatment of toxic goitre, is well recognized to reduce the size of the thyroid gland. Although its effect in non-toxic nodular goitre has been evaluated in several studies $(8-11)$, very little is known of its efficacy and side effects in non-toxic diffuse goitre. This option is nevertheless pertinent in view of the problems related to long-term $\mathrm{L}-\mathrm{T}_{4}$ suppressive therapy. The aim of our study was to 
evaluate the long-term effect of ${ }^{131}$ I-therapy on thyroid size and function and patient satisfaction in a representative group of patients with non-toxic diffuse goitre.

\section{Patients and methods}

\section{Patients and design}

During the period from 1994 through to 2001, 82 consecutive patients with diffuse non-toxic goitre referred to our endocrinology outpatient clinic were evaluated (Fig. 1). A homogeneous structure of the thyroid gland with the absence of nodules was confirmed by clinical examination, thyroid ultrasonography, as well as $99 \mathrm{mTc}$-pertechnetate scintiscan. The patients, none receiving thyroid medication, were all euthyroid based on clinical judgment and biochemical tests. Treatment indication was the presence of goitre giving rise to cervical compression and/or cosmetic discomfort. Forty-three (52\%) patients were excluded due to negligible symptoms and only a slight thyroid enlargement. Four other patients were referred to thyroid surgery because of aversion against ${ }^{131}$ I-therapy. Pregnancy or contemplation of further pregnancies, as well as lactation and age below 18 years were considered as contraindications to ${ }^{131}$ I-therapy. The remaining 35 patients $(43 \%)$ were treated with ${ }^{131}$ I after written and oral consent. One patient dropped out 3 months after the therapy, leaving 34 patients for the final analysis (Fig. 1). In these individuals - thus comprising a selected group - the median age was 40 years (range: 27-68), and the median initial thyroid volume was $62 \mathrm{ml}$ (range: 21-128). The smallest goitres were found among patients in whom a hemithyroidectomy had previously been performed. Cervical compression was a major complaint and a sensation of globulus was present among $73 \%$ of these patients. The median s-TSH was 0.68 U/l (range: 0.02-1.44), serum free $\mathrm{T}_{4}$-index $\left(\mathrm{s}-\mathrm{FT}_{4} \mathrm{I}\right)$ was $99 \mathrm{nmol} / \mathrm{l}$ (range: 67-167), and serum free $\mathrm{T}_{3}$-index $\left(\mathrm{s}-\mathrm{FT}_{3} \mathrm{I}\right.$ ) was $1.63 \mathrm{nmol} / \mathrm{l}$ (range: 1.10-2.30). Four individuals at the time of treatment had a s-TSH slightly below the normal range, but were characterized as being euthyroid according to normal indexes of the thyroid hormones. Similarly, two individuals with a slightly elevated $\mathrm{s}-\mathrm{FT}_{4} \mathrm{I}$ and $\mathrm{s}-\mathrm{FT}_{3} \mathrm{I}$ respectively, had a normal s-TSH and were therefore accepted for inclusion in the study. Increased serum levels of anti-thyroid peroxidase antibodies (anti-TPOab) were found in 18\% of the study population. None had positive titres of TSH-receptor antibodies (TSH-R-ab). Further characteristics of the study population are given in table 1 , which includes a comparison with the no-treatment group. Patients in the ${ }^{131}$ I-therapy group were significantly older, had larger goitres and longer duration of symptoms. ${\mathrm{L}-\mathrm{T}_{4}}_{4}$ suppressive therapy, previously used in 11 individuals (32\%) with inadequate effect on goitre size, was discontinued at least 3 months prior to the ${ }^{131}$ I-therapy.

Patients were investigated by clinical examination, thyroid ultrasonography and thyroid function tests with regular intervals and for at least 12 months after the ${ }^{131}$ I-therapy. Yearly follow-up continued until the end of the study period. Patients who developed permanent hypothyroidism beyond the first year after the ${ }^{131}$ I-therapy were excluded from further follow-up due to the possible influence on goitre reduction of $\mathrm{L}_{-} \mathrm{T}_{4}$ substitution, but data until that point were used for analysis. Hypothyroidism was treated routinely with $\mathrm{L}_{4} \mathrm{~T}_{4}$ aiming at s-TSH in the normal range. If euthyroidism could be obtained by a low $\mathrm{L}_{-} \mathrm{T}_{4}$ dose, a trial of withdrawal was made within the first year to disclose transient hypothyroidism, in which case the patient remained in the study.

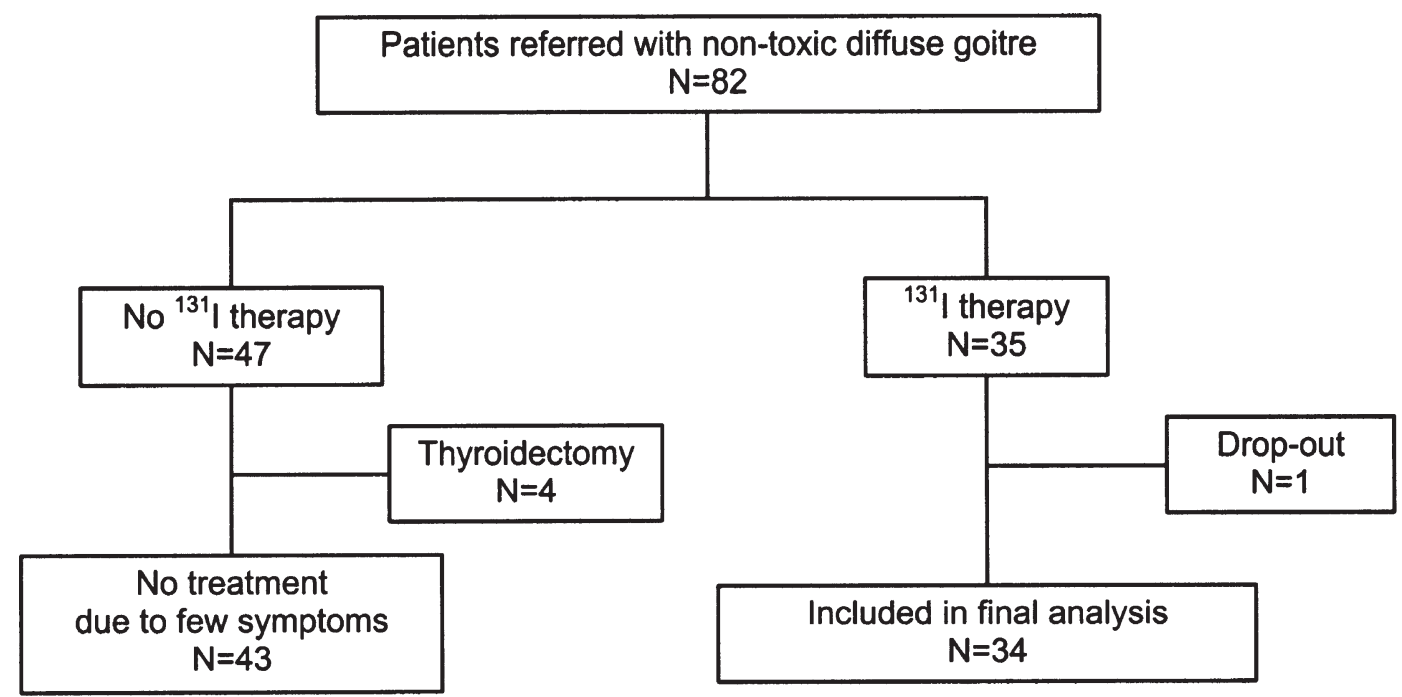

Figure 1 Flowchart of consecutive patients referred with a non-toxic diffuse goitre. 
Table 1 Characteristics of the study population in comparison with the group of patients who received no treatment because symptoms were few or absent.

\begin{tabular}{lccc}
\hline & 131 I-therapy $(n=34)$ & No treatment $(n=43)$ & $\boldsymbol{P}$ value \\
\hline Gender (M/F) & $5 / 29$ & $4 / 39$ & $\mathrm{~ns}$ \\
Age in years (range) & $40(27-68)$ & $36(18-70)$ & $<0.05$ \\
Smokers (\%) & 59 & 49 & $\mathrm{~ns}$ \\
Previous thyroidectomy $(n)$ & 4 & 1 & $\mathrm{~ns}$ \\
Previous L-T4 therapy ( $n)$ & 11 & 5 & $\mathrm{~ns}$ \\
Duration of symptoms in months (range) & $21(2-240)$ & $36(16-74)$ & $<0.05$ \\
Initial thyroid volume in ml (range) & $62(21-128)$ & & $<0.05$ \\
\hline
\end{tabular}

ns, not significant.

\section{Methods}

The ${ }^{131}$ I-therapy was dosed according to a simplified algorithm taking only the thyroid volume into account. According to several studies $(12-14)$ on ${ }^{131}$ I-therapy in hyperthyroid diseases, the use of calculated doses does not carry any advantages compared with fixed doses. Thus, $200 \mathrm{MBq}$ was given to glands $<30 \mathrm{ml}$, $400 \mathrm{MBq}$ to glands in the range $30-60 \mathrm{ml}$, and $600 \mathrm{MBq}$ if the volume was $>60 \mathrm{ml}$. A maximum activity of $600 \mathrm{MBq}$, which is the maximum outpatient activity, was set. The ${ }^{131}$ I-therapy was given orally on an outpatient basis.

The thyroid volume was measured as previously described (15) by an accurate planimetric scanning procedure using a specially equipped ultrasound compound scanner (type 1846; Brüel \& Kjær, Copenhagen, Denmark) mounted with a $5-\mathrm{MHz}$ transducer on a static scanner arm. The average error of this method is approximately $7 \%$ with a median difference of $+2 \mathrm{ml}$ (range: -27 to 12 ) (15). Mean thyroid volume in an adult population without clinically overt goitre is $19 \mathrm{ml}$ (range: $10-28$ ) (15).

Serum concentrations of $\mathrm{T}_{4}$ (normal range: 65$135 \mathrm{nmol} / \mathrm{l}$ ), $\mathrm{T}_{3}$ (normal range $1.00-2.10 \mathrm{nmol} / \mathrm{l}$ ), and TSH (normal range: $0.30-4.0 \mathrm{mU} / \mathrm{l}$ ) were determined by in-house methods, as was the $\mathrm{T}_{3}$ resin uptake (normal range: $0.80-1.25$ ). $\mathrm{s}_{\mathrm{s}}-\mathrm{FT}_{4} \mathrm{I}$ and $\mathrm{s}-\mathrm{FT}_{3} \mathrm{I}$ were calculated multiplying serum $\mathrm{T}_{4}$ and $\mathrm{T}_{3}$ levels respectively, by the $\mathrm{T}_{3}$ resin uptake. The interassay coefficients of variation were below $10 \%$ for all assays. Euthyroidism was defined as s- $\mathrm{FT}_{4} \mathrm{I}$ and s-FT $\mathrm{I}_{3} \mathrm{I}$ within the normal range; hyperthyroidism was defined as increased $\mathrm{s}-\mathrm{FT}_{4} \mathrm{I}$ and/or $\mathrm{s}-\mathrm{FT}_{3} \mathrm{I}$ in addition to a decreased s-TSH level; permanent hypothyroidism was defined as a decreased s-FT $\mathrm{I}_{4}$ and an elevated s-TSH level. Serum anti-TPOab were determined by the RIA DYNO test (Brahms Diagnostica, Berlin, Germany; negative: $<60 \mathrm{U} / \mathrm{ml}$ ), and s-TSH-R-ab were determined by the TRAK assay (Henning Berlin GMBH, Germany; negative: <9 U/l, borderline positive: 9-14 U/l).

To evaluate the subjective benefit of the ${ }^{131}$ I-therapy, goitre-related symptoms were registered by Visual Analogue Scale (VAS). Before treatment and at the end of follow-up each individual was asked to indicate on the VAS ranging from '0' to '10' (arbitrary units), the degree of cervical compression and cosmetic discomfort. ' 0 ' represented no complaints and ' 10 ' the worst possible degree of compression/discomfort.

The study was approved by the Local Ethics Committee of the County of Funen, Denmark (trial number 2002-0118).

\section{Statistical analysis}

Data are presented as medians (range) and means ( \pm S.D. or S.E.). Non-parametric or parametric (ANOVA) statistical tests were used depending on the normality of the data. Simple regression analysis was used to test correlations. To compare frequencies, $\chi^{2}$ test was used. The cumulated incidence rates of hypothyroidism were calculated by a survival analysis in a Kaplan-Meier plot. VAS score data were compared by use of the Wilcoxon test. The level of statistical significance was chosen as a $P$ value $<0.05$.

\section{Results}

The median ${ }^{131}$ I activity was $600 \mathrm{MBq}$ (range: 200600). The median follow-up time was 36 months (range: 12-84). One female patient was treated twice with ${ }^{131} \mathrm{I}$. Despite a goitre reduction from 73 to $36 \mathrm{ml}$ two years after the initial treatment with $600 \mathrm{MBq}$ ${ }^{131} \mathrm{I}$, a second dose of $600 \mathrm{MBq}{ }^{131} \mathrm{I}$ was given due to persistent cervical compression. A further reduction to $17 \mathrm{ml}$ within one year by this second treatment led to the disappearance of her symptoms. Data from this individual obtained after the second treatment are included in the analysis.

\section{Thyroid volume}

Three months following ${ }^{131}$ I-therapy, the mean goitre size was reduced to $66.4 \pm 2.8 \%$ (S.E.) of the initial volume (Fig. 2). In absolute terms, the volume diminished from $67.9 \pm 28.5 \mathrm{ml}$ (S.D.) to $43.4 \pm 18.7 \mathrm{ml}$ (S.D.) $(P<0.001)$. Further reduction was observed with continued follow-up. By six months the goitre volume was halved, on average, and after three years, only 


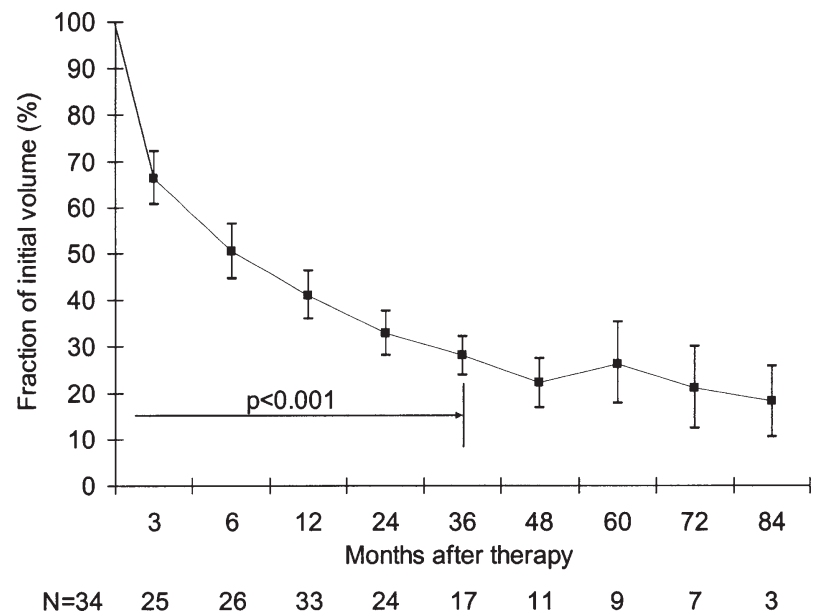

Figure 2 Effect of ${ }^{131}$ I-therapy on the mean percentage goitre reduction. Bars represent the $95 \%$ confidence interval. After three years no further significant goitre reduction was observed. Figures at the bottom are number of patients examined on each occasion. Only data from individuals remaining euthyroid were analysed since appearance of permanent hypothyroidism excluded the patient from further follow-up in the study.

$28.1 \pm 2.0 \%$ (S.E.) remained of the initial goitre mass $(P<0.001$, Fig. 2). Beyond three years, no significant additional reduction could be demonstrated (Fig. 2). By the final ultrasonography performed at the end of follow-up no thyroid nodule had emerged, and goitre could no longer be demonstrated (i.e. gland volume within the normal range) in 26 patients $(76 \%)$. At the 1-year follow-up, a significant inverse correlation was found between the initial goitre size and the percentage volume reduction $(r=-0.44, \quad P=0.01$; Fig. 3); i.e. with increasing size, the efficacy of ${ }^{131}$ I-therapy on the goitre reduction was attenuated. However, such a relationship was absent at three years (Fig. 3), suggesting that, with time, patients with a large goitre achieve a similar relative goitre reduction as those with a smaller gland.

\section{Thyroid function}

All patients were euthyroid at the time of treatment. Ten patients (29\%) experienced a temporary thyrotoxicosis within three months after therapy, two of whom had anti-TPOab present before therapy. In all cases, the thyrotoxicosis was of mild nature and self-limiting. It was probably caused by dumping of stored thyroid hormones into the circulation, since de novo appearance of TSH-R-ab was not encountered in any case, making a Graves'-like condition unlikely. None developed anti-TPOab within the follow-up period.

In two individuals $(6 \%)$, transient hypothyroidism appeared within six months after ${ }^{131}$ I-therapy. In each case, euthyroidism was achieved with a small dose of $\mathrm{L}_{-} \mathrm{T}_{4}$, which could be discontinued successfully after a short period of time. As regards permanent
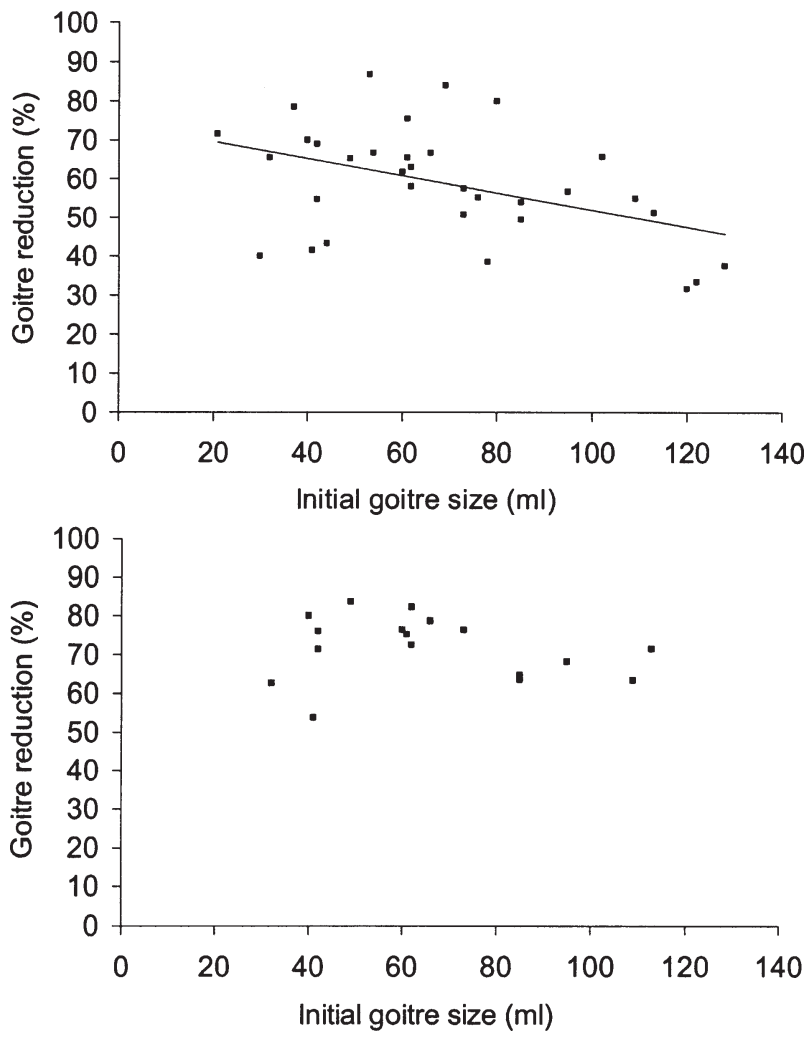

Figure 3 Relationship between the initial goitre size and the relative reduction obtained by ${ }^{131}$ I-therapy. At one year of follow-up (top), the effect was significantly attenuated with increasing goitre size $(r=-0.44, P=0.01)$. Such a correlation was absent at three years of follow-up (bottom).

hypothyroidism following ${ }^{131}$ I-therapy, the cumulated rates were $15 \%$ after 12 months, $27 \%$ after 24 months and 36\% after 36 months (Fig. 4). No individual developed hypothyroidism after that time. All cases with permanent hypothyroidism were treated with $\mathrm{L}_{-} \mathrm{T}_{4}$

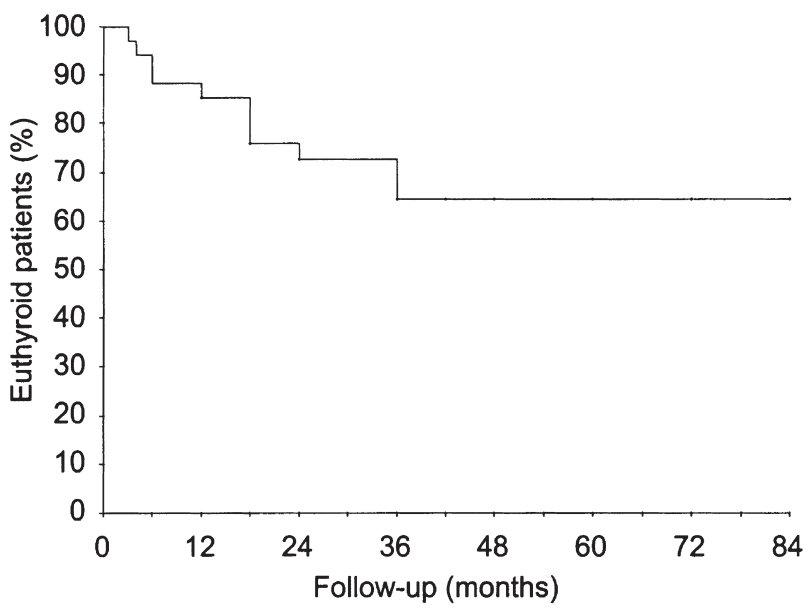

Figure 4 The cumulated incidence of permanent hypothyroidism after ${ }^{131}$ I-therapy of non-toxic diffuse goitre shown in a KaplanMeier survival analysis. After 36 months, $36 \%$ of the patients were hypothyroid with no additional cases. 
substitution, resulting in complete relief of any hypothyroid symptoms.

\section{Effect on goitre symptoms}

Reflecting the degree of cervical compression and the cosmetic discomfort, the median VAS scores at baseline were 7.0 (range: $0.0-10.0$ ) and 5.5 (range: 0.0-10.0) respectively (Fig. 5). No significant correlation was found between the individual VAS scores and the goitre size. Thus, individuals with a relatively small goitre had symptoms of the same magnitude as those with larger glands. Nine patients $(26 \%)$ had a slight pain of the thyroid gland shortly after ${ }^{131}$ I-therapy, probably due to a mild and transient radiation thyroiditis. This condition was promptly and efficiently treated with non-steroidal anti-inflammatory drugs. Temporary
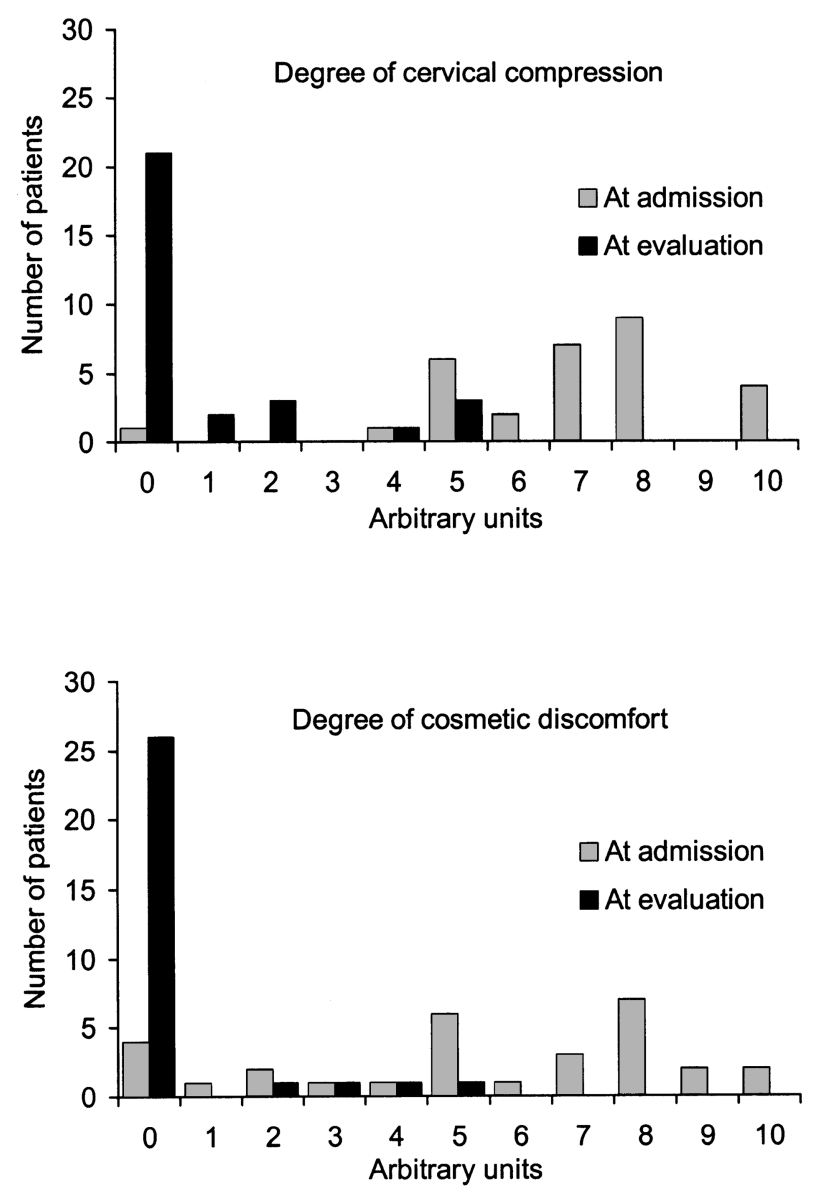

Figure 5 Severity of symptoms caused by the goitre and the effect of ${ }^{131} \mathrm{I}$-therapy evaluated by the Visual Analogue Scale (VAS) principle. ' 0 ' denotes no complaints and '10' the worst possible degree of symptoms. The figure shows the VAS scores related to the cervical compression (top) and the cosmetic complaints (bottom) respectively. For both parameters, the VAS scores obtained at evaluation were significantly reduced in comparison with the pre-treatment scores $(P<0.001)$. Data were not obtained in four patients. thyrotoxicosis coexisted in only one of these patients. None encountered an acute increase of the goitre accompanied by respiratory distress. Goitre-related symptoms were highly improved at the final evaluation, both with regard to cervical compression and cosmetic discomfort. Thus, the median VAS scores of both variables were significantly reduced to 0.0 (range: 0.0-5.0) $(P<0.001$, compared with pre-treatment scores; Fig. 5).

\section{Discussion}

Thyroid enlargement is found among $15-23 \%$ of women in Denmark, a mild iodine-deficient area until use of iodized salt was initiated a few years ago (16). Thyroid nodules are absent in approximately one third of these individuals (16), thereby making nontoxic diffuse goitre a very common condition, at least in regions with a similar iodine intake. If goitre-related symptoms emerge it becomes a clinical problem. The present study is the first to demonstrate the long-term benefits and adverse effects of ${ }^{131}$ I-therapy in patients with a non-toxic diffuse goitre. While reports on nontoxic nodular goitre have been quite numerous, only two small studies $(17,18)$ regarding non-toxic diffuse goitre, with a short follow-up period have been published. Validated by the pre-treatment VAS scores, our patients had significant cervical compression and/or cosmetic symptoms. Interestingly and well known to most thyroidologists, the severity of the symptoms was not related to the goitre size. Like almost all other studies within this area, our study did not include a control group. Since ${ }^{131}$ I-therapy in numerous series $(8-11,19,20)$, albeit mostly in uncontrolled designs, has been shown to reduce goitre size, we found it unethical to randomize patients with goitre-related symptoms to no treatment. The patients who received no treatment were unsuitable as controls, since these individuals had smaller glands and fewer symptoms. Since studies on the natural history of this disease indicate a goitre growth of $4-20 \%$ annually $(4,21)$, it is most likely that the pronounced goitre reduction found in this study was due to the influence of the ${ }^{131}$ I-therapy. Within three months after treatment, the goitre was, on average, reduced by a third and by $70 \%$ after three years. Taking into account the natural goitre growth rate, the effect may have been even higher. Thus, it is evident that the volume reduction achieved by ${ }^{131}$ I-therapy is more pronounced in nontoxic diffuse glands than in non-toxic multinodular goitres $(9,10)$, comparable to the situation in toxic goitres $(22,23)$. Furthermore, our study suggests that ${ }^{131} \mathrm{I}-$ therapy has a more prolonged goitre-reducing effect in diffuse as compared with nodular glands and demonstrates a 'catch-up' effect in large goitres. As has also been shown for multinodular glands $(9,19)$, the relative reduction was attenuated with increasing goitre 
size in the short term. However, three years after the

${ }^{131}$ I-therapy the size of large goitres was reduced to a similar extent as smaller ones in relative terms. This is most likely explained by the radiation being more uniformly distributed in diffuse goitres, perhaps thereby resulting in indefinite thyroid destruction. In addition to the marked goitre reduction the rate of satisfaction with the ${ }^{131}$ I-therapy was very high among the patients. This issue has not been evaluated to any greater extent in earlier studies. Since VAS scores were not systematically monitored during follow-up we do not know for certain when the initial complaints disappeared. At the final examination the VAS scores were, with few exceptions, zero. Retrospective evaluation suggested this to have been achieved within the first year of treatment.

Adverse effects were few. Mild thyroid pain, occasionally encountered with ${ }^{131}$ I-therapy, was self-limiting and was easily treated with weak analgesics. Thirtysix percent of the patients became hypothyroid three years after the ${ }^{131}$ I-therapy. It is likely that this rate will increase with longer follow-up and be comparable to what is seen after ${ }^{131}$ I-therapy in Graves' disease, where virtually all patients become hypothyroid with life-long follow-up (22). Should hypothyroidism ensue, this is easily treated with $\mathrm{L}_{-} \mathrm{T}_{4}$, which might reduce the gland size even further.

Should ${ }^{131} \mathrm{I}$ then be the standard treatment recommendation for the non-toxic diffuse goitre? We know from recent surveys that there is no consensus regarding the treatment of non-toxic goitre $(24,25)$. In contrast to the use in multinodular goitres, it has been shown in several studies $(1-4)$ that $\mathrm{L}_{-} \mathrm{T}_{4}$ suppressive therapy does have some effect in the reduction of the non-toxic diffuse goitre, but the effect is modest and long term side-effects should indeed be taken into account $(5,6)$. While the present study describes the long-term benefit of ${ }^{131}$ I-therapy of non-toxic diffuse goitre we cannot yet tell about the risks of thyroidal and extrathyroidal ${ }^{131}$ I-induced cancers. Nevertheless, from several large-scale studies on ${ }^{131}$ I-therapy in hyperthyroid diseases we know that these risks are theoretical or at least of very little clinical relevance (26-28). Since any of the three treatment options, $\mathrm{L}_{-} \mathrm{T}_{4}$ suppressive therapy, thyroidectomy and ${ }^{131}$ I-therapy, reduces the size of non-toxic diffuse goitre, the choice must, at present, be based on individual factors. In our clinic, ${ }^{131}$ I-therapy has been a first line recommendation in patients with a non-toxic goitre for several years. The long-term efficacy of this treatment, in patients with a non-toxic diffuse goitre, is now further supported by the present study. Randomized studies that compare the various treatments, both with regard to the goitre reduction, goitre recurrence, cost-benefit, and, in particular, with the degree of patient satisfaction and quality of life are certainly needed to make the choice more evidence-based.

\section{Acknowledgements}

This study was supported by research grants from 'The Agnes and Knut Mørks Foundation', 'The A.P. Møller Support Foundation' and 'The Novo Nordisk Foundation'.

\section{References}

1 Perrild H, Hansen JM, Hegedüs L, Rytter L, Holm B, Gundtofte E \& Johansen K. Triiodothyronine and thyroxine treatment of diffuse non-toxic goitre evaluated by ultrasonic scanning. Acta Endocrinologica $1982 \mathbf{1 0 0} 382$-387.

2 Bongers H, Hotze LA, Schmitz R \& Joseph K. LT 4 -monopreparation versus $\mathrm{LT}_{4}-\mathrm{LT}_{3}$-compound preparation in the treatment of diffuse endemic goitre. Acta Endocrinologica $1986113242-248$.

3 Hansen JM, Kampmann J, Madsen SN, Skovsted L, Solgaard S, Grytter C, Grontvedt T \& Rasmussen SN. L-thyroxine treatment of diffuse non-toxic goitre evaluated by ultrasonic determination of thyroid volume. Clinical Endocrinology $1979101-6$.

4 Berghout A. Wiersinga WM, Drexhage HA, Smits NJ \& Touber JL. Comparison of placebo with L-thyroxine alone or with carbimazole for treatment of sporadic non-toxic goitre. Lancet 1990 336 193-197.

5 Parle JV, Maisonneuve P, Sheppard MC, Boyle P \& Franklyn JA. Prediction of all-cause and cardiovascular mortality in elderly people from one low serum thyrotropin result: a 10-year cohort study. Lancet $2001 \mathbf{3 5 8} 861-865$.

6 Uzzan B, Campos J, Cucherat M, Nony P, Boissel JP \& Perret GY. Effects on bone mass of long term treatment with thyroid hormones: a meta-analysis. Journal of Clinical Endocrinology and Metabolism $1996814278-4289$.

7 al Suliman NN, Ryttov NF, Qvist N, Blichert-Toft M \& Graversen HP. Experience in a specialist thyroid surgery unit: a demographic study, surgical complications, and outcome. European Journal of Surgery $199716313-20$.

8 de Klerk JM, Van Isselt JW, van Dijk A, Hakman ME, Pameijer FA, Koppeschaar HP et al. Iodine-131 therapy in sporadic nontoxic goiter. Journal of Nuclear Medicine 199738 372-376.

9 Le Moli R, Wesche MF, Tiel-Van Buul MM \& Wiersinga WM. Determinants of longterm outcome of radioiodine therapy of sporadic non- toxic goitre. Clinical Endocrinology $1999 \quad \mathbf{5 0}$ 783-789.

10 Nygaard B, Hegedüs L, Gervil M, Hjalgrim H, Søe-Jensen P \& Hansen JM. Radioiodine treatment of multinodular non-toxic goitre. British Medical Journal 1993307 828-832.

11 Wesche MF, Tiel-Van Buul MM, Lips P, Smits NJ \& Wiersinga WM. A randomized trial comparing levothyroxine with radioactive iodine in the treatment of sporadic nontoxic goiter. Journal of Clinical Endocrinology and Metabolism 2001 86 998-1005.

12 Kok SW, Smit JW, de Craen AJ, Goslings BM, Eck-Smit BL \& Romijn JA. Clinical outcome after standardized versus dosimetric radioiodine treatment of hyperthyroidism: an equivalence study. Nuclear Medicine Communications 200021 1071-1078.

13 Leslie WD, Ward L, Salamon EA, Ludwig S, Rowe RC \& Cowden EA. A randomized comparison of radioiodine doses in Graves' hyperthyroidism. Journal of Clinical Endocrinology and Metabolism $2003 \mathbf{8 8} 978-983$.

14 Jarløv AE, Hegedüs L, Kristensen LO, Nygaard B \& Hansen JM. Is calculation of the dose in radioiodine therapy of hyperthyroidism worth while? Clinical Endocrinology 199543 325-329.

15 Hegedüs L, Perrild H, Poulsen LR, Andersen JR, Holm B, Schnohr P, Jensen G \& Hansen JM. The determination of thyroid volume by ultrasound and its relationship to body weight, age, and sex in normal subjects. Journal of Clinical Endocrinology and Metabolism 198356 260-263.

16 Knudsen N, Bülow I, Jørgensen T, Laurberg P, Ovesen L \& Perrild H. Goitre prevalence and thyroid abnormalities at 
ultrasonography: a comparative epidemiological study in two regions with slightly different iodine status. Clinical Endocrinology $200053479-485$.

17 Hegedüs L \& Bennedbæk FN. Radioiodine for non-toxic diffuse goitre. Lancet $19973 \mathbf{3 5 0} 409-410$.

18 Nygaard B, Faber J, Veje A \& Hansen JE. Thyroid volume and function after 131I treatment of diffuse non-toxic goitre. Clinical Endocrinology $1997 \mathbf{4 6} 493-496$.

19 Bonnema SJ, Bertelsen H, Mortensen J, Andersen PB, Knudsen DU, Bastholt L \& Hegedüs L. The feasibility of high dose iodine 131 treatment as an alternative to surgery in patients with a very large goiter: effect on thyroid function and size and pulmonary function. Journal of Clinical Endocrinology and Metabolism 1999 $843636-3641$.

20 Huysmans DA, Hermus AR, Corstens FH, Barentsz JO \& Kloppenborg PW. Large, compressive goiters treated with radioiodine. Annals of Internal Medicine 1994121 757-762.

21 Berghout A, Wiersinga WM, Smits NJ \& Touber JL. Interrelationships between age, thyroid volume, thyroid nodularity, and thyroid function in patients with sporadic nontoxic goiter. American Journal of Medicine 199089 602-608.

22 Nygaard B, Hegedüs L, Gervil M, Hjalgrim H, Hansen BM, Søe-Jensen P \& Hansen JM. Influence of compensated radioiodine therapy on thyroid volume and incidence of hypothyroidism in Graves' disease. Journal of Internal Medicine 1995238 491-497.
23 Nygaard B, Hegedüs L, Ulriksen P, Nielsen KG \& Hansen JM. Radioiodine therapy for multinodular toxic goiter. Archives of Internal Medicine $19991591364-1368$.

24 Bonnema SJ, Bennedbæk FN, Wiersinga WM \& Hegedüs L. Management of the nontoxic multinodular goitre: a European questionnaire study. Clinical Endocrinology 200053 5-12.

25 Bonnema SJ, Bennedbæk FN, Ladenson PW \& Hegedüs L. Management of the nontoxic multinodular goiter: A North American Survey. Journal of Clinical Endocrinology and Metabolism 200287 $112-117$.

26 Franklyn JA, Maisonneuve P, Sheppard M, Betteridge J \& Boyle P. Cancer incidence and mortality after radioiodine treatment for hyperthyroidism: a population-based cohort study. Lancet 1999 $3532111-2115$.

27 Hall P, Berg G, Bjelkengren G, Boice JD Jr, Ericsson UB, Hallquist A et al. Cancer mortality after iodine-131 therapy for hyperthyroidism. International Journal of Cancer $1992 \mathbf{5 0}$ $886-890$.

28 Ron E, Doody MM, Becker DV, Brill AB, Curtis RE, Goldman MB et al. Cancer mortality following treatment for adult hyperthyroidism. Cooperative Thyrotoxicosis Therapy Follow-up Study Group. JAMA $1998 \mathbf{2 8 0} 347-355$.

Received 18 August 2003

Accepted 9 December 2003 